\title{
Development of a Simulation Program to Optimise Process Parameters of Steam Power Cycles
}

\author{
Harshal D Akolekar ${ }^{a^{*}}$, P Srinivasan $^{b}$, Jagat Sesh Challa ${ }^{c}$ \\ ${ }^{a, b}$ Department of Mechanical Engineering, Birla Institute of Technology \& Science, Pilani, India, 333031 \\ ${ }^{c}$ Department of Computer Science \& Information Systems, Birla Institute of Technology \& Science, Pilani, India
}

\begin{abstract}
Conventional coal-based thermal power plants have an average overall efficiency in the range of 35-38\%. Any increase in the percent efficiency of these power plants, is subjected to constraints posed by maximum and minimum temperatures, which are restricted by the creep property of materials and ambient temperature, respectively. Hence, an increase of efficiency beyond certain limits is not possible without optimising the process parameters associated with reheat and regenerative cycles. In this work, an attempt is made to optimise reheat and regenerative cycle process parameters such as, reheat pressure, tapping pressure of bled steam, and mass fraction of bled steam, in order to achieve maximum cycle efficiency. The optimisation of the process parameters was achieved by developing a simulation program using Microsoft Visual Studio. This program takes into account isentropic efficiencies of turbines and pumps and pressure drop in the boiler, and it can be used to simulate the optimum operating conditions of multi-stage reheat \& regenerative cycle based thermal power plants. A comparison between the efficiencies of eight kinds of steam power cycles, at optimised conditions, has been made for different boiler pressures and steam temperatures at the turbine inlet. This comparison can aid power plant designers in choosing appropriate steam power cycles for a given set of operating conditions. It is observed that the results obtained from the program, such as, the optimum reheat pressures for two stage reheat cycles and optimum bled steam tapping pressures for two stage regenerative cycles are in good agreement with the published literature.
\end{abstract}

Keywords: Reheat cycle, Regenerative cycle, Process parameters, Optimisation, Efficiency, Power plant.

\section{Introduction}

Energy conservation and meticulous utilisation of power, is one of the challenges the world is facing right now, and will do so in the future. Researchers are finding numerous ways to utilise energy more efficiently and extract more from a current system by making several modifications. The simple Rankine cycle is the basic thermodynamic cycle on which thermal power plants work. However, the simple Rankine cycle alone is not used in power plants as it does not provide maximum possible efficiency for the given operating conditions. Various modifications such as, the addition of open and closed feed water heaters, re-heaters, etc., are made with a view of augmenting the efficiency and improving other operating

* Corresponding author.

E-mail: hakolekar@gmail.com

(c) 2014 International Association for Sharing Knowledge and Sustainability

DOI: $10.5383 /$ ijtee.08.01.007 parameters such as quality of steam at the turbine exhaust. Once re-heaters and feed water heaters are in place, optimising process parameters is essential to obtain maximum thermal efficiency for given boiler pressure, condenser pressure and steam temperature at the turbine inlet.

Researchers, with the help of certain assumptions, have been working process parameters' optimisation of single and multistage regenerative cycles. Haywood [1] developed analytical solutions to determine the optimum range of feed heating for a system having a finite number of feed water heaters. Haywood [2] investigated the performance of single pump and split pump schemes in regenerative steam cycles by developing analytical methods. Horlock [3] performed a simplified analysis to determine the overall efficiency of a recuperative combined gas turbine and steam power plant with and without feed water 
heaters. Weir [4] discussed the relationships obtained for the optimum distribution of heater enthalpy rise in a contact heater train for various kinds of regenerative cycles.

Investigations have been carried out to improve the efficiency of reheat cycles also. Habib et al. [5] have worked on the optimisation of reheat pressures of thermal power plants with the help of exergy balance equations and first law efficiency. Ust et al. [6] studied the effect of boiler pressure, temperature and irreversibility on the thermal efficiency, work output and optimal reheat pressures for two stage reheat cycles. Habib and Zubair [7] have done a second-law based thermodynamic analysis of regenerative-reheat cycle power plants. Dincer and Al-Muslim [8] have done a thermodynamic analysis of a single reheat cycle for steam power plants based on the first and second laws of thermodynamics. Horlock [9] developed analytical solutions to analyse one stage reheat and regenerative cycle. Habib et al. [10] have done an extensive thermodynamic analysis on the optimisation of two stage reheat pressures for reheat-regenerative cycle based power plants. They have developed analytical solutions for the cycle and have performed a thorough irreversibility analysis and concluded that the first and second law efficiencies are more strongly influenced by higher reheat pressure than the lowerreheat pressure. Many researchers have used genetic algorithms to optimise energy consumption and system configuration in power plants [11-15]. Hajabdollahi et al. [16] have used a genetic algorithm to maximise the efficiency and simultaneously minimize the operating cost of steam power plants. Energy optimisation is a very important in non-power plant sectors like that of heat engines as well [17].

From the existing literature, it is observed that many researchers have attempted to optimise the process parameters of reheat cycles or regenerative cycles considering them independently. However, most of the thermal power plants work on combined reheat and regenerative cycles. Hence, it is essential to optimise the process parameters of power plants with combined reheat and regenerative cycles. Limited literature is available regarding optimisation of multi-stage combined reheat and regenerative cycles, and not many attempts have been made to develop a program for the optimisation of process parameters of such cycles. An attempt has been made, in this work, to develop a program to optimise process parameters of combined reheat and regenerative cycles, in order to maximise the cycle efficiency. The program is developed in Microsoft Visual Studio and the programming language used is Visual C\#.NET. Thermodynamic steam tables [18] have been used for calculating the optimum process parameters. The optimised process parameters obtained from the developed program, have been compared with the data available in the existing literature.

\section{Algorithm and program development}

In order to maximise thermal efficiency, by optimising the process parameters, algorithms have been developed using fundamental equations and laws of thermodynamics which are applied to steam power cycles. Separate modules have been developed for the simple Rankine cycle, one / two stage(s) regenerative cycle, one / two stage(s) reheat cycle, one stage reheat $\&$ one stage regenerative cycle and two stage reheat $\&$ two stage regenerative cycle. Similar modules, for subcritical thermal power plants, can be developed for more complicated situations as well. Operating or input data such as boiler pressure, condenser pressure, steam temperature at the turbine inlet, isentropic efficiency of the turbine and pump and pressure drop in the boiler is entered using a Graphical User Interface. If the cycle has a re-heater, the reheat temperature is to be entered also. This input data is capable of analysing the actual steam power cycle used in thermal power plants. For the development of the program, a library of functions has been developed and database of thermodynamic steam tables has been made; from which the program automatically draws thermodynamic data.

The flowchart shown in Fig.1 depicts one of the algorithms developed, applicable to one stage reheat $\&$ one stage regenerative cycle. To start with, the reheat pressure is initialised to the boiler pressure. Next, the Open Feed Water Heater (OFWH) pressure is initialised to the reheat pressure and is reduced in steps of $100 \mathrm{kPa}$ and efficiency $\left(\eta_{i j}\right)$ is calculated every time the OFWH pressure is decremented. If $\eta_{i j}$ is greater than the efficiency obtained in any previous iteration $\left(\eta_{\max }\right)$, then the optimum conditions $\left(\mathrm{P}_{\mathrm{OFWH}}\right.$ Opt , $\left.\mathrm{P}_{\mathrm{R} \text { Opt }}, \mathrm{m}_{1 \text { Opt }} \& \eta_{\max }\right)$ get updated. When the OFWH pressure falls below condenser pressure, the reheat pressure is decremented by $100 \mathrm{kPa}$ and the OFWH pressure is reinitialised to the reheat pressure. This process continues until the reheat pressure falls below the condenser pressure. Iteration numbers $(i, j)$ get updated as shown in Fig. 1. This algorithm has been developed by decrementing the intermediate pressures by $100 \mathrm{kPa}$. However, it is possible to reduce the decrement in pressure below $100 \mathrm{kPa}$ to get better results; but the change in efficiency takes place only in the third decimal. Therefore, a decrement in the intermediate pressures by $100 \mathrm{kPa}$ is a good approximation.

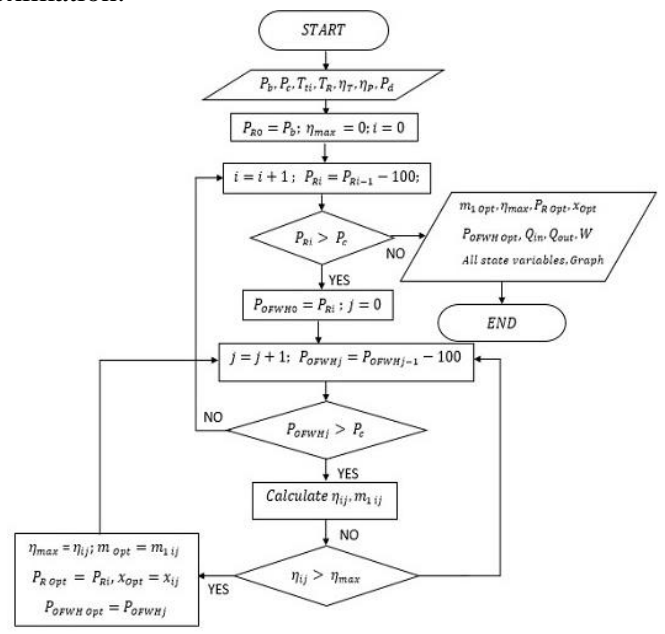

Fig. 1. One stage reheat $\&$ one stage regenerative cycle algorithm.

The program returns the following output: maximum efficiency, optimum operational pressures of the various kinds of heaters, and the mass fraction of bled steam. State variables $(T, P, s, h)$ at the entrance and exit point of each of the components and $Q_{\text {in }}, Q_{\text {out }}$ and $\mathrm{W}$ are calculated. Users are also given $\mathrm{T}-\mathrm{s}, \mathrm{h}-\mathrm{s}, \mathrm{P}-\mathrm{h}$ and several other charts to aid them in analysis. 


\section{An application of the program - one stage reheat $\&$ one stage regenerative cycle}

In order to illustrate the working of the algorithm and program, an example is provided. Based on the input parameters in Table 1, and with the help of the Eqs. 1 to 5, maximum efficiency of $40.39 \%$ is obtained for the optimised process parameters, which are shown in Table 2. The schematic diagram (Fig. 2) and a $T-s$ diagram (Fig. 3) are shown for the one stage reheat $\&$ one stage regenerative cycle.

Table 1. Input parameters for one stage reheat $\&$ one stage regenerative cycle.

\begin{tabular}{ll}
\hline Parameter & Value \\
\hline$P_{b}$ & $18000 \mathrm{kPa}$ \\
$P_{c}$ & $10 \mathrm{kPa}$ \\
$T_{t i}$ & $540{ }^{\circ} \mathrm{C}$ \\
$\eta_{T}$ & $85 \%$ \\
$\eta_{P}$ & $85 \%$ \\
$T_{R}$ & $486{ }^{\circ} \mathrm{C}$ \\
$P_{d}$ & $500 \mathrm{kPa}$ \\
\hline
\end{tabular}

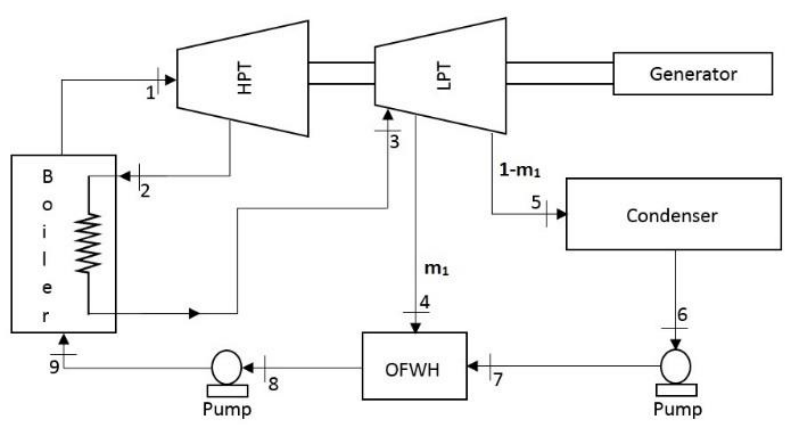

Fig. 2. Schematic diagram of one stage reheat $\&$ one stage regenerative cycle.

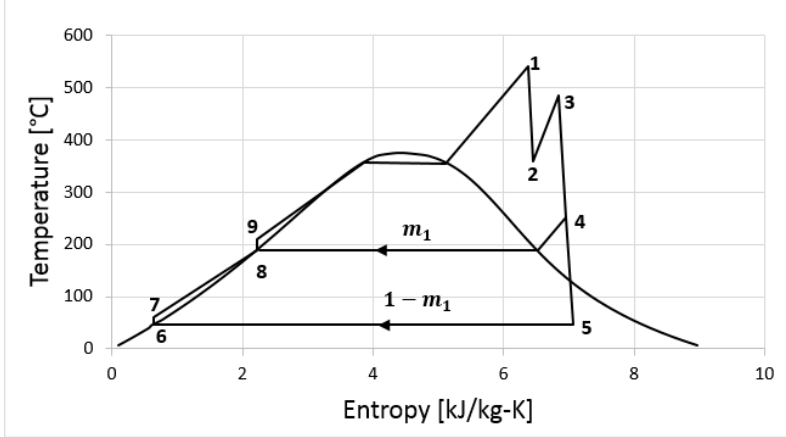

Fig. 3. T-s diagram of one stage reheat $\&$ one stage regenerative cycle.

$\mathrm{W}=\left(\mathrm{h}_{1}-\mathrm{h}_{2}\right)+\left(\mathrm{h}_{3}-\mathrm{h}_{4}\right)-\left(\mathrm{h}_{9}-\mathrm{h}_{8}\right)+\left(1-\mathrm{m}_{1}\right) \times$

$$
\left[\left(\mathrm{h}_{4}-\mathrm{h}_{5}\right)-\left(\mathrm{h}_{7}-\mathrm{h}_{6}\right)\right] \mathrm{kJ} / \mathrm{kg}
$$

$\mathrm{Q}_{\mathrm{in}}=\left(\mathrm{h}_{1}-\mathrm{h}_{9}\right)+\left(\mathrm{h}_{3}-\mathrm{h}_{2}\right) \mathrm{kJ} / \mathrm{kg}$

$\mathrm{Q}_{\text {out }}=\left(1-\mathrm{m}_{1}\right) \times\left(\mathrm{h}_{5}-\mathrm{h}_{6}\right) \mathrm{kJ} / \mathrm{kg}$

Energy balance for the OFWH gives

$\mathrm{m}_{1}=\left(\mathrm{h}_{8}-\mathrm{h}_{7}\right) /\left(\mathrm{h}_{4}-\mathrm{h}_{7}\right)$

$\eta=\mathrm{W} / \mathrm{Q}_{\mathrm{in}}$
Table 2. Output parameters of one stage reheat $\&$ one stage regenerative cycle

\begin{tabular}{ll}
\hline Parameter & Value \\
\hline$P_{b}$ & $18000 \mathrm{kPa}$ \\
$P_{c}$ & $10 \mathrm{kPa}$ \\
$T_{t i}$ & $540{ }^{\circ} \mathrm{C}$ \\
$T_{R}$ & $540{ }^{\circ} \mathrm{C}$ \\
$\eta_{T}$ & $100 \%$ \\
$\eta_{P}$ & $100 \%$ \\
\hline
\end{tabular}

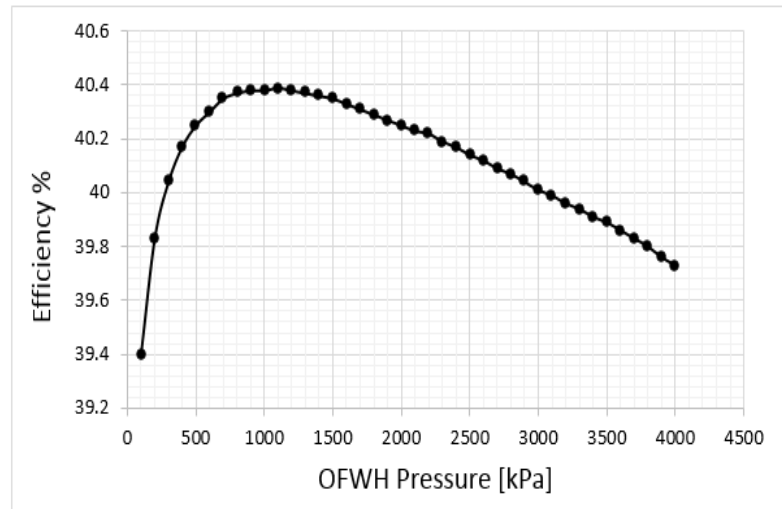

Fig. 4. Efficiency vs. OFWH pressure diagram.

If the reheat pressure is constant at $4000 \mathrm{kPa}$ and the OFWH pressure is decremented from $4000 \mathrm{kPa}$, in $100 \mathrm{kPa}$ intervals, a trend is obtained, as shown in Fig. 4. As the OFWH pressure is reduced, the efficiency increases up to a peak value of $40.39 \%$. Then it starts decreasing to a minimum value of $39.4 \%$ for the given reheat pressure. Tapping bled steam at $4000 \mathrm{kPa}$ does not allow steam to expand sufficiently in the turbine, as work output is reduced by diverting bled steam at a higher pressure. Similarly, if steam is tapped off at a pressure lower than $1100 \mathrm{kPa}$, the efficiency decreases. This graph highlights the importance of optimising process parameters, as the efficiency can vary by at least $1 \%$ if the process parameters aren't optimised.

\section{Program validation}

In order to validate the present work, a comparison is made with the existing literature [10, 18]. An algorithm has been developed to arrive at isoefficiency contours, as shown in Fig. 5 , for different values of first stage and second stage reheat pressures, while the boiler pressure is constant. An isoefficiency contour is a curve on which points having the same efficiency lie. These curves have been generated for ideal conditions assuming perfect reheat, no pressure drop in the boiler and isentropic efficiency equal to $100 \%$, as shown in Table 3 . 
Table 3. Input parameters for two stage reheat cycle

\begin{tabular}{ll}
\hline Parameter & Value \\
\hline$\eta_{\max }$ & $40.39 \%$ \\
$P_{R}$ opt & $4000 \mathrm{kPa}$ \\
$P_{\text {OFWH Opt }}$ & $1100 \mathrm{kPa}$ \\
$m_{1}$ opt & 0.2077 \\
$x_{\text {Opt }}$ & 0.887 \\
$W$ & $1190.37 \mathrm{~kJ} / \mathrm{kg}$ \\
$Q_{\text {in }}$ & $2947.37 \mathrm{~kJ} / \mathrm{kg}$ \\
$Q_{\text {out }}$ & $1757.23 \mathrm{~kJ} / \mathrm{kg}$ \\
\hline
\end{tabular}

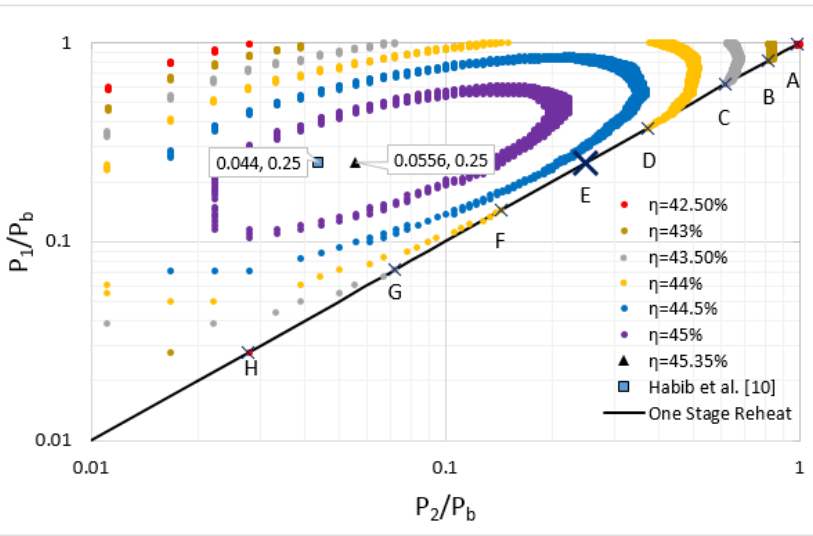

Fig. 5. Isoefficiency contours - two stage reheat cycle.

To begin with, the first stage reheat and second stage reheat pressures are initialised to the boiler pressure. The second stage reheat pressure is reduced in steps of $100 \mathrm{kPa}$ until it is less than the condenser pressure. The thermal efficiency is calculated each time the second stage reheat pressure is decremented. Then the program reduces the first stage reheat pressure by $100 \mathrm{kPa}$ and the second stage reheat pressure is reinitialised to the first stage reheat pressure. The second stage reheat pressure is decremented until it is less than the condenser pressure. This process goes on until the first stage reheat pressure falls below the condenser pressure. Using the data generated, isoefficiency contours for different values of $P_{1} / P_{b}$ and $P_{2} / P_{b}$ ratios have been plotted.

Isoefficiency contours obtained from the present work are compared with similar plots developed by Habib et al. [10]. They found out that the maximum efficiency for a two stage reheat cycle occurs when the first stage reheat pressure is $25 \%$ of the boiler pressure and the second stage reheat pressure is $4.4 \%$ of the boiler pressure. Maximum efficiency, as per the present work, occurs when the first stage and second stage reheat pressures are $25 \%$ and $5.56 \%$ of the boiler pressure, respectively. It is observed that the results are in close agreement with the existing literature.

The straight line $P_{1} / P_{b}=P_{2} / P_{b}$ represents the case of a one stage reheat cycle. The constant efficiency contour of $\eta=$ $44.2 \%$ is tangential to this line at point $\mathrm{E}(0.25,0.25)$, or $25 \%$ of the boiler pressure, as indicated in Fig. 5. This is the maximum efficiency achievable for a one stage reheat cycle at the given operating conditions. As the reheat pressure is decreased from the boiler pressure to the condenser pressure, it can be seen that the efficiency increases from A to E and then decreases from $\mathrm{E}$ to $\mathrm{H}$, which is similar to the trend observed for a one stage regenerative cycle. The above results are in good agreement with Haywood [19], who states that the optimum reheat pressure for a single stage reheat cycle falls between 20-25\% of the boiler pressure. The point $A(1,1)$ corresponds to the simple Rankine cycle efficiency.

\section{Results and discussion}

\subsection{Two stage regenerative cycle}

In the present analysis, isoefficiency contours have been generated for a two stage regenerative cycle, as shown in Fig. 6 . The contours have been generated for ideal conditions and for the input as shown in Table 4. The process of generation of the contours is similar to the two stage reheat cycle. Instead of first stage and second stage reheat pressures, first stage and second stage OFWH pressures are used. Using the data generated, isoefficiency contours for different values of $P_{H P} / P_{b}$ and $P_{L P} / P_{b}$ ratios have been plotted.

Table 4. Input parameters for two stage regenerative cycle

\begin{tabular}{ll}
\hline Parameter & Value \\
\hline$P_{b}$ & $20000 \mathrm{kPa}$ \\
$P_{C}$ & $25 \mathrm{kPa}$ \\
$T_{t i}$ & $60{ }^{\circ} \mathrm{C}$ \\
$T_{R}$ & $600{ }^{\circ} \mathrm{C}$ \\
$\eta_{T}$ & $100 \%$ \\
$\eta_{P}$ & $100 \%$
\end{tabular}

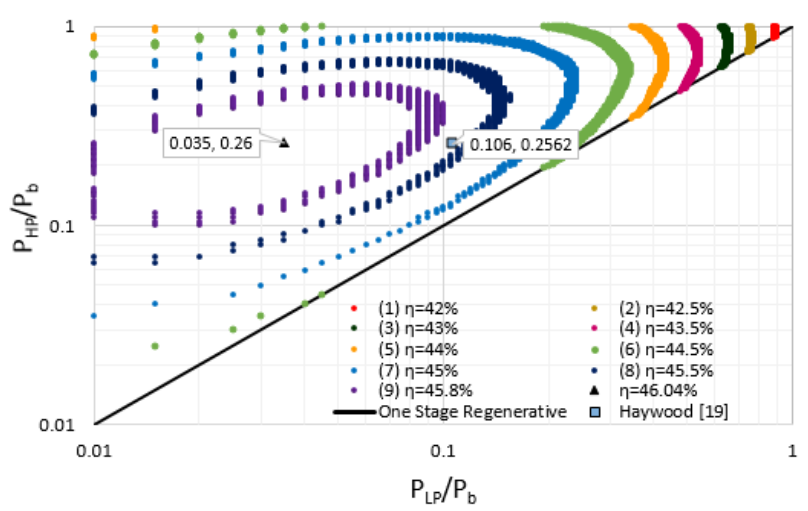

Fig. 6. Isoefficiency contours - two stage regenerative cycle.

Schaff originally made an assumption that along a turbine expansion line the difference between the local enthalpy $(h)$ and the liquid enthalpy $\left(h_{f}\right)$ remains unchanged, i.e. $h-h_{f}=$ constant [9]. From Fig. 7, this assumption implies $\left(h_{1}-h_{8}\right)=$ $\left(h_{2}-h_{7}\right)=\left(h_{3}-h_{6}\right)=\left(h_{4}-h_{5}\right)=$ constant. This assumption was used by Haywood [1,19] to derive an expression, Eq. 6, for calculating the optimum pressures of nstage ideal regenerative cycle. $\Delta t_{b c}$ and $\Delta t_{f w}$ are illustrated by Fig. 7, more clearly. 


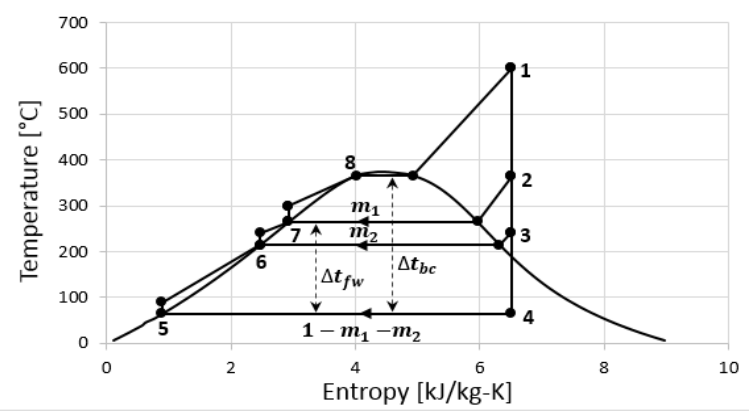

Fig. 7. T-s diagram of two stage regenerative cycle

$\Delta t_{f w}=\mathrm{n} /(\mathrm{n}+1) \Delta t_{b c}$

when $\mathrm{n}=1, \Delta t_{f w 1}=1 / 2 \Delta t_{b c}$;

and when $\mathrm{n}=2, \Delta t_{f w 2}=2 / 3 \Delta t_{b c}$;

Based on the above expression, and for the input parameters (Table 4) of a two stage regenerative cycle; to get maximum efficiency, the bled steam should be tapped from the turbine at pressures of $5125 \mathrm{kPa}$ and $2120 \mathrm{kPa}$. The maximum efficiency, thus obtained, is $45.62 \%$. From Fig. 6 , the program gives a maximum efficiency of $46.04 \%$. The difference of $0.42 \%$ can be attributed to the fact that the program takes into account the actual specific enthalpy drop of steam at different stages of regeneration and that Schaff's assumption is found to be valid over a limited pressure range, usually at lower pressure levels [9]. From Fig. 6, it can be concluded that the optimum bled steam tapping pressures for a two stage regenerative cycle are $26 \%$ and $3.5 \%$ of the boiler pressure, for the given operating conditions. The program has the capability of taking into account actual conditions, whereas Eq. 6 has been developed for ideal conditions only. Such isoefficiency contours can be generated for any operating conditions.

\subsection{Comparison of various steam power cycles}

Fig. 8 represents the maximum possible efficiency, at optimised conditions, for each of the steam power cycles, at a particular boiler pressure; which is varied from $10000 \mathrm{kPa}$ to $22000 \mathrm{kPa}$ in steps of $1000 \mathrm{kPa}$. The condenser pressure and steam temperature at turbine inlet are kept constant at $10 \mathrm{kPa}$ and $540{ }^{\circ} \mathrm{C}$, respectively. The isentropic efficiency of $100 \%$ has been assumed for the turbines and pumps of all the cycles. For any boiler pressure, it is observed that the two stage reheat $\&$ two stage regenerative cycle gives maximum efficiency. Two stage reheat \& one stage regenerative cycle has the second highest efficiency for all boiler pressures. It is observed that for higher boiler pressures, two stage regenerative cycle has slightly greater efficiency than one stage reheat \& one stage regenerative cycle; whereas one stage reheat $\&$ one stage regenerative cycle is more efficient at lower boiler pressures. Similarly, one stage regenerative cycles are more efficient at higher pressures than a two stage reheat cycle; whereas the latter is slightly more efficient at boiler pressures below 12000 $\mathrm{kPa}$. At pressures above $19000 \mathrm{kPa}$, the one stage regenerative cycle is nearly $0.6 \%$ more efficient than the two stage reheat cycles. Simple Rankine cycles give the least efficiency for all boiler pressures. One stage reheat cycles give the second lowest efficiency.

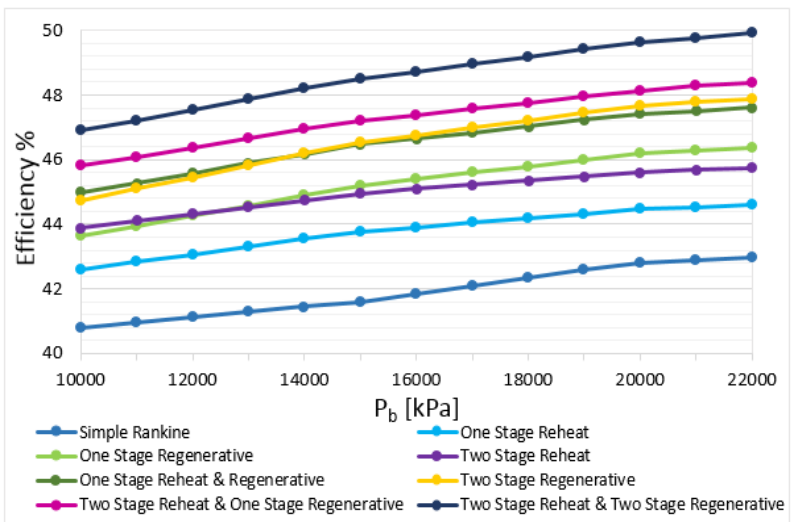

Fig. 8. Effect of boiler pressure on thermal efficiency for different steam power cycles with $T_{t i}=540^{\circ} \mathrm{C}$.

Many existing thermal power plants are operating with steam temperature of $540{ }^{\circ} \mathrm{C}$ at the turbine inlet. However, more recently, power plants with new materials are capable of withstanding steam temperature of $600{ }^{\circ} \mathrm{C}$ at the turbine inlet. Hence, an attempt is made to study the efficiency change for different steam power cycles for the maximum permissible steam temperature of $600^{\circ} \mathrm{C}$, keeping the condenser pressure at $10 \mathrm{kPa}$. The trends observed, which are shown in Fig. 9, for two stage reheat $\&$ two stage regenerative cycle, two stage reheat $\&$ one stage regenerative cycle, one stage reheat cycle and simple Rankine cycle are the same as compared to the case of $T_{t i}=540^{\circ} \mathrm{C}$. The trends for the other four cycles are similar. However, the pressure at which the efficiency of two stage regenerative cycle and the one stage reheat $\&$ one stage regenerative cycle becomes equal, gets shifted to a higher value. Similarly, the efficiency of the one stage regenerative cycle and the two stage reheat cycle becomes equal at 19000 $\mathrm{kPa}$. Similar graphs can be generated for other operating conditions as well, taking into account isentropic efficiencies and pressure drops.

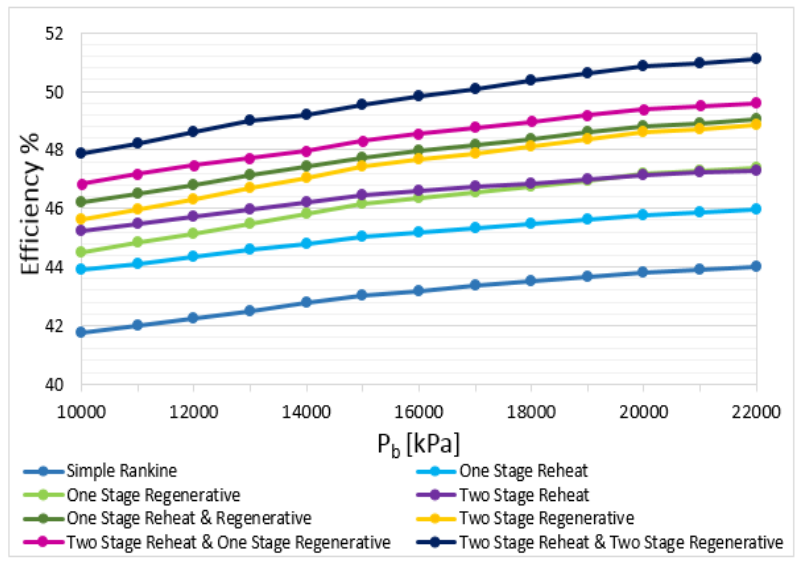

Fig. 9. Effect of boiler pressure on thermal efficiency for different steam power cycles with $T_{t i}=600^{\circ} \mathrm{C}$. 


\section{Conclusions}

The decision of choosing an appropriate steam power cycle, such as a reheat cycle, a regenerative cycle or a combined reheat \& regenerative cycle, for a given set of operating conditions, to increase thermal efficiency, is always an important and challenging task. In order to maximise thermal efficiency, the developed program is useful in identifying the type of cycle, along with the optimum operating conditions. The program can be used by designers for an initial feasibility analysis in thermal power plants to investigate the effect of cost structure. The developed program would help for the enhancement of energy generation by power plants, and thus benefits investment returns. From the present work, it is observed that the optimum reheat pressures for a two stage reheat cycle are in close agreement with the reported values. The maximum efficiency obtained for given boiler pressure, steam temperature at the turbine inlet and condenser pressure for a two stage regenerative cycle is better than those mentioned in the literature. The developed program has potential for simulating various kinds of vapour power cycles for fluids other than water, binary vapour cycles and supercritical cycles.

\section{Nomenclature}

$\mathrm{P}$ pressure, $\mathrm{kPa}$

$\mathrm{P}_{\mathrm{b}} \quad$ boiler pressure, $\mathrm{kPa}$

$\mathrm{P}_{\mathrm{c}} \quad$ condenser pressure, $\mathrm{kPa}$

$\mathrm{P}_{\mathrm{d}} \quad$ pressure drop in boiler, $\mathrm{kPa}$

$\mathrm{P}_{1} \quad$ first stage reheat pressure, $\mathrm{kPa}$

$\mathrm{P}_{2} \quad$ second stage reheat pressure, $\mathrm{kPa}$

$\mathrm{P}_{\mathrm{HP}}$ first stage $\mathrm{OFWH}$ pressure, $\mathrm{kPa}$

$\mathrm{P}_{\mathrm{LP}} \quad$ second stage OFWH pressure, $\mathrm{kPa}$

$\mathrm{T}$ temperature, ${ }^{\circ} \mathrm{C}$

$\mathrm{T}_{\mathrm{ti}} \quad$ temperature at turbine inlet, ${ }^{\circ} \mathrm{C}$

$\mathrm{T}_{\mathrm{R}} \quad$ reheat temperature, ${ }^{\circ} \mathrm{C}$

$\eta \quad$ cycle efficiency

$\eta_{\mathrm{T}} \quad$ isentropic efficiency of turbine

$\eta_{P} \quad$ isentropic efficiency of pump

$\mathrm{m}_{1}$ mass fraction of bled steam at first stage of regeneration

$m_{2}$ mass fraction of bled steam at second stage of regeneration

$\mathrm{h}$ specific enthalpy, $\mathrm{kJ} / \mathrm{kg}$

$\mathrm{x}$ quality of steam at turbine exhaust

W net work output, $\mathrm{kJ} / \mathrm{kg}$

$\mathrm{Q}_{\text {in }}$ heat input, $\mathrm{kJ} / \mathrm{kg}$

$\Delta \mathrm{t}_{\mathrm{bc}}$ difference between boiler saturation temperature and condenser temperature, ${ }^{\circ} \mathrm{C}$
$\Delta \mathrm{t}_{\mathrm{fw}}$ total temperature rise of feedwater, ${ }^{\circ} \mathrm{C}$

\author{
Subscripts \\ i iteration number of reheat \\ j iteration number of OFWH \\ Opt optimum value \\ max maximum \\ Acronyms \\ $\begin{array}{ll}\text { OFWH } & \text { Open Feed Water Heater } \\ \text { HPT } & \text { High Pressure Turbine } \\ \text { LPT } & \text { Low Pressure Turbine }\end{array}$
}

\section{References}

[1] R.W. Haywood. A generalized analysis of the regenerative steam cycle for a finite number of heaters. Proceedings of the Institution of Mechanical Engineers. 1949;161:157164, DOI: 10.1243/PIME_PROC_1949_161_016_02

[2] R.W. Haywood. Thermodynamic study of the number and positioning of the feed pumps in the feed train of a regenerative steam cycle. Proceedings of the Institution of Mechanical Engineers. 1957;171:747-756, DOI: 10.1243/PIME_PROC_1957_171_062_02

[3] J.H. Horlock. The use of feed heating in the steam cycle of a combined cycle power plant. Proceedings of the Institution of Mechanical Engineers Part A: Journal of Power and Energy. 1991;205:207-215, DOI: 10.1243/PIME_PROC_1991_205_029_02

[4] C.D. Weir. Optimization of heater enthalpy rises in feedheating trains. Proceedings of the Institution of Mechanical Engineers. 1960;1794:769-796, DOI: 10.1243/PIME_PROC_1960_174_057_02

[5] M.A. Habib, S.A.M. Said, I. Al-Zaharna. Optimization of reheat pressures in thermal power plants. Energy. 1995;20(6):555-565.

DOI: 10.1016/0360-5442(94)00087-J

[6] Y. Ust, G. Gonca, H.K. Kayadelen. Determination of optimum reheat pressures for single and reheat irreversible Rankine cycle. J. of the Energy Institute. 2011:84 (4):215219, DOI 10.1179/174396711X13116932751994

[7] M.A. Habib, S.M Zubair. Second-law-based thermodynamic analysis of regenerative- reheat Rankinecycle power plants: Energy. 1992;17:295-301, DOI: 10.1016/0360-5442(92)90057-7

[8] I. Dincer, H. Al-Muslim. Thermodynamic analysis of reheat cycle steam power plants. Journal of Energy Research. 2001;25:727-739, DOI: $10.1002 /$ er. 
[9] J.H. Horlock. Simplified analyses of some vapour power cycles. Proceedings of the Institution of Mechanical Engineers, Part A: Journal of Power and Energy. 1996;210: 191-202,

DOI: 10.1243/PIME_PROC_1996_210_032_02717

[10] M.A. Habib, S.A.M. Said, I. Al-Zaharna. Thermodynamic optimization of reheat regenerative thermal power plants. Applied Energy. 1999;63:17-34,

DOI: S0306-2619(99)00017-3

[11] H. Hajabdollahi, P. Ahmadi, I. Dincer. An exergy-based multi objective optimization of a heat recovery steam generator (HRSG) in a combined cycle power plant (CCPP) using evolutionary algorithm. Int. J. of Green Energy. 2011;8:44-64,

DOI: $10.1080 / 15435075.2010 .529779$

[12] I Bertini, et al. Soft computing based optimization of combined cycled power plant start-up operation with fitness approximation methods. Applied Soft Computing.2011;11: 4110-4116,

DOI:10.1016/j.asoc.2011.02.028

[13] P. Ahmadi, I. Dincer. Thermodynamic analysis and thermoeconomic optimization of a dual pressure combined cycle power plant with a supplementary firing unit. Energy Conversion and Management. 2011;52:2296-2308, DOI:10.1016/j.enconman.2010.12.023
[14] M. Valdes, M.D. Duran, A. Rovira. Thermoeconomic optimization of combined cycle gas turbine power plants using genetic algorithms. Applied Thermal Engineering. 2003;23:2169-2182, DOI: $10.1016 /$ S1359-4311(03)00203-5

[15] M.M. Rashidi, et al. Parametric analysis and optimization of regenerative Clausius and organic Rankine cycles with two feedwater heaters using artificial bees colony and artificial neural network. Energy. 2011;36(9):5728-5740, DOI:10.1016/j.energy.2011.06.036

[16] F. Hajabdollahi, Z. Hajabdollahi, H. Hajabdollahi. Soft computing based multi-objective optimization of steam cycle power plant using NSGA-II and ANN. Applied Soft Computing. 2012;12(11):3648-3655, DOI: $10.1016 /$ j.asoc.2012.06.006

[17] C. Nylund, M.E.H. Assad. Energy Optimization of Heat Engine with Infinite Heat Capacity Reservoirs. Int. J. of Thermal \& Environmental Engineering. 2013;6(1): 21-26, DOI: 10.5383/ijtee.06.01.004

[18] Richard E. Sonntag, Claus Borgnakke, Gordon J. Van Wylen: Fundamentals of Classical Thermodynamics, seventh ed., Wiley, India, 2010.

[19] R.W. Haywood: Analysis of Engineering Cycles, fourth ed., Pergamon Press. Oxford, 1991. 